\title{
PRÁTICAS E DISCURSOS DE USUÁRIOS DE UMA ONG/AIDS SOBRE ATIVISMO
}

\author{
Maio Spellman Quirino de Farias \\ Magda Dimenstein \\ Universidade Federal do Rio Grande do Norte, Natal, Brasil
}

\begin{abstract}
RESUMO: Esse trabalho objetiva discutir os resultados de uma pesquisa que investigou as concepções e práticas de ativismo anti-AIDS entre os usuários vinculados a uma ONG/AIDS, na cidade de Campina Grande/PB. Realizamos entrevistas com 31 usuários, 20 homens e 11 mulheres. Dois aspectos relacionados às concepções e prática do ativismo entre os usuários sobressaem-se: o enfraquecimento/desmotivação para realização de um ativismo coletivo e a adesão ao tratamento como ferramenta de motivação para a luta anti-AIDS. Observa-se que a ONG pesquisada está atravessada no seu cotidiano pelos problemas da falta de adesão e desmobilização, na medida em que se afastou de uma agenda de mobilização para aproximar-se de setores governamentais que repassam financiamentos, através da execução de projetos. Como conseqüência direta, a ONG não vem conseguindo mobilizar portadores para as atividades de rua.
\end{abstract}

PALAVRAS-CHAVE: Ativismo; AIDS; terceiro setor; Psicologia.

\section{PRACTICE AND DISCOURSE OF USERS OF AN NGO/AIDS ABOUT ACTIVISM}

ABSTRACT: The aim of this work is to discuss the results of a research study that investigated the concepts and practices related to anti-AIDS activism amongst members of an NGO/AIDS in the city of Campina Grande-PB. We interviewed 31 members, 20 men and 11 women. Two aspects related to the concept and practice of activism among them were pointed out: the weakening/lack of motivation for collective activism and the compliance to the treatment as a tool for motivation in the anti-AIDS battle. We observed that the NGO under study faces daily problems of compliance and lack of mobilization, as it detaches itself from the mobilization agenda in order to align itself with the governmental sectors that provide financing through the development of projects. As a direct consequence, the NGO has been unable to mobilize the affected individuals for street activities.

KEYWORDS: Activism; AIDS; third sector; Psychology.

Ao longo de quase três décadas de luta anti-AIDS, as ONGs/AIDS demarcaram seu território de atuação no campo de batalha contra a epidemia da AIDS, tornandose um espaço de referência para as pessoas que convivem e vivem com HIV/ AIDS. São um instrumento de luta contra preconceitos, discriminações, desinformações e omissões e objetivam lutar contra a epidemia e suas consequiências (Câmara \& Lima, 2000).

Não por acaso, o Brasil é um dos cinco países do mundo que distribuem preservativos e medicação gratuitamente para portadores e doentes de AIDS e isso não foi conquistado devido à boa vontade política das autoridades, mas, antes de tudo, graças ao ativismo presente em toda uma década de luta caracterizada pelas manifestações de rua (passeatas, vigílias e abaixo-assinados), criação de Fóruns institucionais de discussão sobre a doença e, principalmente, consolidação de políticas públicas em HIV/AIDS.

Durante esse período, observou-se a institucionalização do terceiro setor em HIV/AIDS como decorrência da globalização e de sua influência nos movimentos sociais no final da década passada e no inicio desta. Essa institucionalização se deu através da execução de projetos, os quais passaram a ser vitais para a existência de algumas ONGs. Obviamente que se deu também através dos órgãos governamentais. Sustentam, Castro e Silva (2005) que a dinâmica estabelecida entre o governo brasileiro, por meio do Programa Nacional de AIDS, e os grupos organizados da sociedade civil construiu uma resposta nacional à epidemia da AIDS. Uma destas respostas foi o financiamento de ações, estabelecendo plenamente a parceria entre Estado/ONGs.

Neste contexto de movimentos sociais "enjaulados" pela institucionalização de entidades e indivíduos e de um terceiro setor ainda atônito diante das demandas que surgem constantemente numa velocidade quase inimaginável, o ativismo anti-AIDS assumiu novas configurações: o portador do vírus da AIDS viu-se envolvido num ativismo institucional através do qual, enquanto 
público alvo, as licitações governamentais captam recursos visando à aquisição de medicamentos, por exemplo. Em torno dele, consolida-se o mercado de produção, consultoria e execução de projetos e mantêm-se boa parte das próprias ONGs que atualmente se configuram como estruturas que funcionam através destes projetos. Ao gerenciar esse "mercado", algumas transformaram-se em empresas e os portadores em meros coadjuvantes, visto que o ativismo de rua, talvez o mais eficiente, vem dando lugar progressiva e sorrateiramente ao ativismo de gabinete que motiva o portador a aderir apenas aos programas governamentais de assistência e tratamento e aos programas institucionais de consultoria e execução de projetos.

$\mathrm{O}$ ativismo atual anti-AIDS aponta um grande paradoxo: de um lado, tem-se o portador do vírus HIV/AIDS, que é assistido pela ONG e pelos programas, e que vem recebendo assessoria de todos os tipos, além dos medicamentos; de outro, há a estrutura da maioria das ONGs que não consegue dialogar e ampliar a interface portador/ONG de modo cotidiano e constante. Nesse meio, o Estado coloca-se como mediador e, com seu viés neoliberal, prioriza respostas imediatistas às necessidades que vão surgindo, sem uma preocupação com os seus efeitos.

Acredita-se que esse modo atual de ativismo antiAIDS ou de funcionamento institucional anti-AIDS tem problemas porque constrói uma estratégia básica para enfraquecer e despolitizar o terceiro setor, especificamente as ONGs/AIDS. Embora estrategicamente as ONGs desenvolvam ações harmônicas, integradoras e de parcerias, em detrimento da ação estatal, ao mesmo tempo, mascaram o desemprego e desempenham atividades que deveriam ser públicas, dando-lhes um caráter privado, tal como a distribuição de cestas básicas, dentre outras atividades de mesmo cunho. Além disso, re-mercantilizam os serviços sociais a partir do momento em que recebem verbas para execução de projetos sociais e filantropizam as respostas às questões sociais quando vão atender à população excluída ou semi-integrada, um quase não-cidadão que não tem acesso à saúde e aos serviços básicos de atenção (Montaño, 2003). Nesse sentido, as ONGs/AIDS, em sua grande parte, não apenas consolidam a reestruturação moderna do capital como fomentam a privatização da seguridade e das políticas sociais e assistenciais.

Pesquisas recentes publicadas apontam as ONGs da área de saúde como as mais dependentes de recursos públicos e que essa parceria é responsável tanto pelo sucesso atual do Programa Nacional de DST/AIDS quanto pela viabilização de idéias inovadoras para o combate à epidemia. Sustentam essas pesquisas que as ONGs atuam onde os gestores não conseguem e isso fomenta intercâmbio de informações e de ações entre gestores e ONGs (Castro \& Silva, 2005).
Todas as questões acima levantadas levaram-nos a mapear a nova estrutura ONGuiana que rompeu com o caráter caritativo, assumindo uma gestão semi-governamental, consolidada na prestação de serviços terceirizados, especialmente identificar o que as está levando a "se afastar de sua agenda de mobilização política, de resistência coletiva e de intervenção, e a se voltar para a agenda dos governos e dos setores governamentais que repassam financiamentos" (Terto Jr., 2004).

Com base nisso, desenvolvemos uma investigação com o objetivo de pesquisar e problematizar as concepções e práticas de ativismo anti-AIDS entre os usuários vinculados a uma ONG/AIDS, do interior da Paraíba, na cidade de Campina Grande.

\section{Objetivos e Método}

A pesquisa teve início com visitas, previamente agendadas, à instituição no segundo semestre de 2004. Após aprovação da entidade e do comitê de ética da Universidade Federal do Rio Grande do Norte (UFRN), as entrevistas foram realizadas, seguindo um roteiro semiestruturado, com 31 usuários da referida entidade, 20 homens e 11 mulheres. Entre esses usuários, não se encontravam dirigentes da instituição nem responsáveis pela coordenação de qualquer projeto.

O instrumento de coleta de dados foi construído para atender aos objetivos da pesquisa, qual seja o de delinear o perfil do usuário inserido na instituição, assim como a investigação da prática do ativismo anti-AIDS nos seguintes aspectos: identificação das concepções de ativismo antiAIDS; como os usuários avaliam as práticas (se ativistas ou não) atualmente realizadas pelo grupo; investigação dos aspectos do funcionamento da vida orgânica da instituição, relacionando-os ao favorecimento ou não da criação de novas estratégias de ações anti-AIDS.

Para analisar os dados obtidos através das entrevistas, apoiamo-nos no método de análise das práticas discursivas, proposto por Spink (2000), numa abordagem qualitativa de entender e fazer pesquisa científica. A operacionalização dessa análise consiste no delineamento de categorias/temas gerais que surgem a partir dos dados das entrevistas, refletindo os objetivos da pesquisa. Depois, foi realizado um depuramento das categorias através de mapas de associação de idéias (Spink \& Lima, 2000).

\section{Resultados}

Foram realizadas 31 entrevistas com 20 usuários do sexo masculino e 11 do sexo feminino. As tabelas a seguir distribuirão os participantes por faixa etária, escolaridade, estado civil, orientação sexual, habitação, cônjuge, filhos, ocupação, renda pessoal e familiar, benefício, diagnóstico, tratamento e forma de ingresso na instituição. 
Tabela 1

Faixa Etária

\begin{tabular}{lc}
\hline Faixa Etária & Amostra \\
\hline $25-30$ anos & 06 \\
$31-40$ anos & 11 \\
$41-50$ anos & $12(\mathrm{n}=12)$ \\
+50 anos & 02 \\
\hline Total & 31
\end{tabular}

Tabela 2

Escolaridade

\begin{tabular}{lc}
\hline Grau de Estudo & Amostra \\
\hline NSC & 03 \\
NMC & 07 \\
FC & 03 \\
NMI & 04 \\
FI & $10(\mathrm{n}=10)$ \\
Nenhum & 04 \\
Total & 31
\end{tabular}

Nota. Legenda: NSC- Nível superior completo; NMC- Nível médio completo; FC- Fundamental completo; NMINível médio incompleto; FI- Fundamental incompleto.

Tabela 3

Estado Civil

\begin{tabular}{lc}
\hline Categoria & Amostra \\
\hline Casado & 07 \\
União civil & 01 \\
Viúvo* & 06 \\
Solteiro 16 & $(\mathrm{n}=16)$ \\
Separado & 01 \\
\hline Total & 31
\end{tabular}

Nota. *Três tiveram parceiros portadores do HIV.

Tabela 4

Orientação Sexual

\begin{tabular}{lcc}
\hline Categoria & Amostra \\
\hline Heterossexual & $21(\mathrm{n}=21)$ \\
Homossexual & 05 \\
Bissexual & 05 \\
\hline Total & 31 \\
& & \\
& Tabela 5 \\
& Habitação &
\end{tabular}

\begin{tabular}{lc}
\hline Categoria & Amostra \\
\hline Própria & $20(\mathrm{n}=20)$ \\
Alugada & 06 \\
Cedida & 05 \\
\hline Total & 31
\end{tabular}

Tabela 6

Cônjuge

\begin{tabular}{lc}
\hline Categoria & Amostra \\
\hline Sim* & 12 \\
Não & $19(\mathrm{n}=19)$ \\
\hline Total & 31
\end{tabular}

Nota. *Três tiveram parceiros portadores do HIV.

Tabela 7

Filhos

\begin{tabular}{lc}
\hline Categoria & Amostra \\
\hline Sim* & $19(\mathrm{n}=19)$ \\
Não & 12 \\
\hline Total & 31
\end{tabular}

Nota. *Apenas dois são soropositivos.

Tabela 8

Ocupação

\begin{tabular}{lc}
\hline Categoria & Amostra \\
\hline Sim & $29(n=29)$ \\
Não & 02 \\
\hline Total & 31
\end{tabular}

Tabela 9

Renda Pessoal

\begin{tabular}{lc}
\hline Categoria & Amostra \\
\hline $01 \mathrm{SM}$ & $24(\mathrm{n}=24)$ \\
01-03 SM & 03 \\
+ 03 SM & 01 \\
Sem renda & 03 \\
\hline Total & 31
\end{tabular}

Tabela 10

Renda Familiar

\begin{tabular}{lc}
\hline Categoria & Amostra \\
\hline $01 \mathrm{SM}$ & 07 \\
01-03 SM & 08 \\
$+03 \mathrm{SM}$ & 02 \\
Sem renda* & $14(\mathrm{n}=14)$ \\
\hline Total & 31
\end{tabular}

Nota. *Um participante não possui nenhum tipo de renda.

Tabela 11

Benefícios

\begin{tabular}{ll}
\hline Categoria & Amostra \\
\hline Sim* & $24(\mathrm{n}=24)$ \\
Não & 07 \\
\hline Total & 31
\end{tabular}


Farias, M. S. Q. de e Dimenstein, M. "Práticas e discursos de usuários de uma ONG/AIDS sobre ativismo

Nota. *Um participante recebe auxílio bolsa-escola.

Tabela 12

Diagnóstico e Tratamento*

\begin{tabular}{lc}
\hline Tempo & Amostra \\
\hline $01-05$ anos & 09 \\
06-10 anos & $18(\mathrm{n}=18)$ \\
$11-15$ anos & 04 \\
\hline Total & 31
\end{tabular}

Nota. *Estão em tratamento no complexo de atendimento municipal: Serviço de Atendimento Especializado, Atendimento Domiciliar Terapêutico e Hospital Universitário$\mathrm{SAE} / \mathrm{ADT} / \mathrm{HU}$.

Tabela 13

Ingresso na Entidade

\begin{tabular}{lc}
\hline Forma & Amostra \\
\hline Midia & 03 \\
Familia & 01 \\
Serviços de saúde & 13 \\
Amigos & $14(\mathrm{n}=14)$ \\
\hline Total & 31
\end{tabular}

Tabela 14 Apoio Recebido

\begin{tabular}{lc}
\hline Apoio & Amostra \\
\hline Feira & 07 \\
Assessorias & 04 \\
Feira/Assessorias & $14(\mathrm{n}=14)$ \\
Outros* & 01 \\
Nenhum & 05 \\
\hline Total & 31
\end{tabular}

Nota. *Toda e qualquer atividade do Grupo que o participante considerou benéfica.

Tabela 15

Tempo para Procurar a Entidade

\begin{tabular}{lc}
\hline Meses/Anos & Amostra \\
\hline 00M-06M & $22(\mathrm{n}=22)$ \\
$07 \mathrm{M}-24 \mathrm{M}$ & 05 \\
+03 anos & 04 \\
\hline Total & 31
\end{tabular}

De acordo com os dados acima apresentados observa-se que os participantes da pesquisa são majoritariamente heterossexuais, têm entre 41-50 anos, são solteiros com filhos, residem em casa própria, recebem benefício e possuem renda pessoal de 01 salário mínimo. Não completaram o ensino fundamental, chegaram a entidade através de amigos, levaram uma média de 06 meses para procurar o grupo e se tratam contra HIV/AIDS há aproximadamente 10 anos.

Os mapas de associação de idéias apontam para três categorizações: a inserção ao grupo, funcionamento e ações do grupo e concepções e formas de ativismo.

\section{Inserção na Entidade}

As atitudes tomadas quando se descobriram portadores foram variadas. Observamos dentre as mais lembradas: a busca de tratamento e de uma instituição de apoio, busca de informações e busca de orientação com assistente social, psicólogo e advogado:

"Procurei uma ONG para que eu pudesse ter melhor orientação e conhecer outras pessoas que tivesse; para que melhor pudesse lidar com o vírus" (Adamastor $1 / \mathrm{H}$ ).

Foi variado também o tempo levado para procurar a instituição:

"Logo que foi descoberto. No mesmo ano, no mesmo dia porque quando foi descoberto eu recebi autorização para ser internado porque naquela época era assim: tinha que ser internado para poder começar tomar o coquetel ...Eu me internei, passei um mês e seis dias internado, tomando o coquetel e quando eu saí de lá continuei o mesmo tratamento". (Julio/H).

A maior expectativa sobre o que encontrar na entidade residia na distribuição de cestas básicas, orientação das assessorias e encontrar amigos e companhia:
"O que eu esperei encontrar no grupo foi que me serviram, doavam feira; tinha palestra. Esperava en- contrar, isso mesmo que eu estou dizendo, coisas boas como eu encontrei. Porque ter uma feira é uma coisa..." (Altamiro/H).
"Tratei aqui no grupo com a intenção do benefício da minha aposentadoria. Eles me encaminharam ao Advogado que trabalha no grupo . . . e até agora o benefício foi conseguido" (Argeu/H).
"Ter apoio e tenho. Tenho apoio, tenho amigo, amigas também. A gente quando precisar assim, precisando de alguma coisa a gente fala e o que eles podem ajudar, ajuda mas quando ele não pode ele não ajuda" (Soraia/M).

\section{Funcionamento e Ações da Instituição}

Fundado em 1994, a instituição executou, mais recentemente, dois projetos financiados: o projeto Direitos Humanos e Saúde Mental em HIV/AIDS (2000-2004), de Assessoria Jurídica e Psicológica e o Projeto Campina Buddy (2004-2006), de acompanhamento domiciliar aos portadores.

O Projeto Direitos Humanos e Saúde Mental em HIV/AIDS disponibilizou um psicólogo e um advogado aos portadores de HIV/AIDS e aos seus familiares, de 
terça a quinta-feira, no horário comercial, numa parceria com a Organização das Nações Unidas para a Educação, a Ciência e a Cultura (UNESCO) e Programa Nacional de DST/AIDS do Ministério da Saúde. Teve por objetivo reduzir o impacto sócio-econômico causado pela discriminação, preconceito e exclusão dos soropositivos e doentes de AIDS na sociedade, através da defesa dos direitos de cidadania.

O Projeto Campina Buddy, de acompanhamento domiciliar, foi uma parceria da Comunidade Européia com duas ONGs do Rio de Janeiro (Grupo de Pela Vida e o Grupo Arco-Irís) que fundaram aqui no Brasil a Rede Buddy Brasil - RBB. Buddy em inglês significa "companheiro" e foi um termo utilizado no inicio da década de 80, na Europa, para identificar o acompanhamento domiciliar às pessoas que eram portadoras do vírus HIV.

Há um treinamento no qual o Buddy, voluntariamente, compromete-se a visitar durante 8hs/semanais um cliente, portador do vírus, em seu domicilio, dando-lhe um apoio prático-emocional que pode ser além-domicilio, por exemplo, na sessão de cinema ou na consulta médica. Atualmente o Grupo conta com 50 clientes sendo regularmente visitados por seus respectivos Buddies, apesar do fim do projeto.

É certo que o Grupo executou outros projetos, sempre em parceria com a Organização das Nações Unidas (ONU)/United Nations Office on Drugs and Crime (UNDCP), UNESCO e o Ministério da Saúde, além dos supracitados: Formação de agentes multiplicadores/19992000; Assessoria em Orientação Sexual/2000-2001; Sustentabilidade e Cidadania/2002; Eventos e Cidadania/ 2002-2003; Projeto P4: Prevenção contra AIDS para profissionais do sexo/2003-2004.

Outra atividade realizada chama-se Chát, a qual está dirigida aos portadores do HIV do grupo, que tem nessa atividade um momento de encontro e troca de informações sobre HIV/AIDS. Há também os eventos festivos tais como em datas comemorativas, confraternizações juninas e de fim de ano.

Procuramos conhecer a percepção dos usuários a respeito de mudanças no funcionamento da instituição desde o seu ingresso. Eis aqui algumas delas:

"Com certeza que sim. A falta de verbas, de doações, a falta de estímulo que as pessoas não têm mais para lutar. São poucas pessoas, são menas pessoas para lutar contra a AIDS . . . aí eu vejo isso: a falta de estímulo das pessoas; as pessoas não estão mais procurando estar dentro, estar lutando, juntando a equipe, correndo atrás e uma andorinha só não faz verão". (Rubenilda/M).

"Observo sim. O grupo não tem mais a equipe de voluntários que tinha, não funciona mais da maneira que encontrei. Portanto eu me senti desmotivado e não estou mais freqüentando o grupo" (Fagundes/H).
Além dessas, foram relatadas a falta de verbas de manutenção, diminuição de doações, falta de estímulo para a luta, mudanças na reunião do chát, aquisição de equipamentos e mudanças nas assessorias jurídica e em saúde mental, diminuição de voluntários e diminuição da freqüência dos portadores.

Perguntados se observaram alguma mudança nas ações realizadas pela instituição, os usuários responderam afirmativamente e apontaram as seguintes mudanças: aumento na execução de projetos, a diminuição da atividade de rua, diminuição do voluntariado, diminuição da quantidade de cestas básicas distribuídas, melhoria do atendimento das assessorias de uma forma geral. Um participante citou o aumento da opção pelo anonimato, manifestada no apoio dos portadores à execução de projetos pela instituição:

“As ações que eu via ser realizadas pelo grupo era promoção de encontros, doação de cestas básicas, doação de roupas, de calçados. Havia um movimento ...Observo que saiu muito da militância para ir atrás de projetos" (Adalberto/H).

"É uma atividade boa (execução de projetos). É melhor. A pessoa fica mais protegido, mais fechado ... eu mesmo não gosto que todo mundo saiba ...É por isso que na rua,não. É melhor um negócio mais aqui. A pessoa vem aqui,resolve o que tem para resolver e vai embora ...Tem pessoas que não ligam em aparecer, mas tem outras que ligam. É melhor uma coisa aqui dentro do que lá fora na rua”. (Ito/H).

Sobre a avaliação das diferenças identificadas, foram citados aspectos positivos e negativos. Na base dos dois está a execução de projetos. Como aspectos positivos foram relacionados: melhoria da qualidade do atendimento, qualificação e respaldo das ações e aquisição de equipamentos:

“Os projetos contribuem muito. É preciso ter projetos. O grupo está de pé hoje porque existem os projetos: DHSM e agora o Buddy, muitas verbas vêm de projetos... os projetos veio para somar, para contribuir, se bem que o grupo executa o projeto antes de ser... de receber por projeto. O que o grupo faz hoje, enquanto projeto, o Direitos Humanos e Saúde Mental, já fazia antes de existir a parceria com o MS. Foi apenas uma continuidade". (Benedito/H).

Os aspectos negativos estão agregados também à execução de projetos: diminuição das atividades de rua, distanciamento dos portadores, diminuição do número de voluntários, diminuição de promoção de eventos abertos, burocratização da ONG, perda do caráter humano das ações, afastamento grupo/portador e diminuição da freqüência dos portadores no grupo. Outros aspectos negativos apontados foram: rotatividade de pessoal, acomodação individual diante da cronificação da doença e da 
concessão do benefício do Instituto Nacional do Seguro Social (INSS) e abandono da mobilização em virtude da melhoria da qualidade do tratamento:

"O lado negativo é o fato de que essa própria exigência levou a ONG a perder aquela sensibilidade em relação ao atendimento, a convivência com o portador; a humanização. Tornou-se aquela coisa mais burocrática, mais profissional mesmo . . . Se tornou mais parecida com as outras instituições que existe na sociedade que levou apenas a você a ver a instituição como um local de trabalho aonde você tem de cumprir seu horário, aonde você tem uma tarefa a cumprir". (Marlineuza/M).

"Eu acho até que as pessoas se acostumaram a conviver com o HIV ... A gente está se esquecendo de lutar. Se acomodamos com o coquetel, com o salário que recebe de benefício . . . agora infelizmente as pessoas estão se acomodando. Eu acho que está na hora da gente voltar a lutar na verdade, ir para rua gritar que não estamos satisfeitos". (Soares/H).

\section{Ativismo: Concepção e Formas de Participação}

Um dos nossos objetivos foi identificar em que medida os usuários se sentiam motivados para lutar contra a AIDS. A maioria afirmou que são motivados e lutam principalmente aderindo à medicação e orientando pessoas que se descobrem portadores:

"Tomando os medicamentos e pedindo a Deus que um dia chegue ao final de não precisar mais de usar as drogas" (Tamires/M).

"Do jeito que eu me cuido quero fazer força para que todos também se cuidem que é para poder viver mais porque todos aqueles que... muitos aqueles, do meu tempo de quando eu iniciei, que entraram em óbito foi porque não se cuidaram e esse pessoal hoje que pegam o HIV tem que ter orientação segura para poder eles procurar tomar o coquetel corretamente e assistência médica sempre quando é marcado. (Itamar/H).

Buscamos investigar os conceitos e definições de ativismo e a forma de participação entre os usuários. Ativismo surge nas falas ora indicando uma concepção social, quando é definido como uma luta dirigida para prevenção à AIDS, como fazer palestras e dar orientações, ora indicando uma ação médica de adesão ao tratamento e à medicação. A definição de ativista foi muito voltada para a prevenção à AIDS, para a orientação às pessoas que se descobrem portadoras, para unir-se à ONG, ter cuidado com a saúde, aderir ao tratamento, fazer atividade de rua, executar projetos e ter estudo:

"É tomar remédio na hora certa" (Marli/M).

"A maioria das pessoas não sabe o que é isso, como se pega e então a gente vai fazer o quê? A gente vai explicar às pessoas como se pega e como se prevenir ...fazer exame de seis em seis meses, até a pessoa ficar... ver que não tem; então ali já é uma luta". (Deolindo/H).

Duas inquietações suplementares ao questionário ocasionaram novas perguntas. Uma versava sobre execução de projeto e ativismo, perguntando se ao executar projeto o grupo continua ativista. A outra questionava se há diferença entre ativismo de rua e ativismo de execução de projetos. Em relação ao primeiro questionamento, a maioria respondeu que sim porque a execução de projetos proporciona melhoria no atendimento ao portador, bem como qualificação da ONG para gerenciar demandas da luta, além de ser uma forma de ativismo:

"Para ser um ativista pode-se lutar por um projeto, pode-se lutar como ativista de rua sem uma coisa mexer com a outra. Pode-se conciliar . . . São dois tipos de ativismo e pode ser feito. Tranqüilo" (Fernando/H).

Em relação à diferença entre ativismo de rua e ativismo de execução de projetos, a maioria respondeu que são atividades paralelas que se complementam, mas que consolidam pólos opostos entre:

\section{Visibilidade da luta versus anonimato individual:}

A gente não está vendo mais aquele movimento na rua aonde hoje a gente luta contra o preconceito; As pessoas mostram sua cara mas, na verdade, o que a gente está sentindo que escondeu mais e estão esperando mais das ONGs, o próprio portador. Os portadores não estão vindo mais cobrar e dizer. Estão, como eu já disse, com aquela coisa; 'hoje eu tenho um salário, estou vivendo em casa, e adeus. Vocês lutem por mim' e esquecem de vir para rua. (Salvador/ H)".

2. Manifestação pública versus burocracia pertinente à execução de projetos:

"Na rua a gente saía fazendo como uma passeata com panfleto, com bandeira, cartazes, a gente exigia; o que a gente exigia a gente tinha ...[Hoje] Quando eu chego lá estão em reunião de portas fechadas, muitas vezes ninguém sabe nem se eu fui lá porque eu entrei e saí e ninguém me viu". (Andrei/H).

\section{Entre militância versus ativismo:}

"Na verdade a militância e o ativista, existe algo em comum. Agora esse algo em comum é exatamente o que leva você a buscar isso. Agora a partir daquele momento que você busca e que começa a ter conhecimento, que você começa a perceber a demanda, você começa... as necessidades que aquela militância exige aí você precisa crescer dentro daquilo para que você exerça um ativismo". (Eulinda/M). 


\section{Discussão}

De acordo com os resultados anteriormente apresentados, consideramos que as mudanças observadas no cotidiano da ONG pesquisada apresentam tanto aspectos positivos quanto negativos para seus usuários. Entretanto, dois aspectos relacionados às concepções e práticas do ativismo entre os usuários sobressaem-se na nossa análise: o enfraquecimento/desmotivação pela realização de um ativismo de rua e a adesão ao tratamento como ferramenta de motivação para a luta anti-AIDS. Entendemos que ambas são importantes no sentido de dar visibilidade a uma questão que se apresenta atualmente como problemática no cenário de discussões sobre o terceiro setor: a quem estas instituições estão servindo?

Em relação ao primeiro aspecto, trata-se de uma diminuição progressiva de atividades coletivas e da suplantação das ações burocráticas, pertinentes à execução de projetos sobre as ações de rua. Não queremos dizer que a execução de projetos em si é uma tarefa simplesmente burocrática, mas a tendência atual de concentrar as atividades nesse modelo, em nível da ação individual, parece enfraquecer as ações de rua, de caráter mais coletivo. Ou seja, percebemos uma relação direta entre o fortalecimento de tal modelo e o enfraquecimento das estratégias de resistência, de criação de espaços de luta e de agenciamento de possibilidades de transformação das relações de poder, de exclusão, de segregação social. Nesse sentido, os discursos dos participantes refletem os movimentos de captura sofisticados em curso no presente que reforçam dispositivos de identificação e classificação dos portadores do HIV/ AIDS. Tal tendência está diretamente articulada às mudanças observadas nas últimas décadas no modo de funcionamento das políticas sociais atreladas ao neoliberalismo e à globalização. Para Giddens (2003):

"Vivemos num mundo de transformações, que afetam quase todos os aspectos do que fazemos. Para bem ou para mal, estamos sendo impelidos rumo a uma ordem global que ninguém compreende plenamente, mas cujos efeitos se fazem sentir sobre todos nós". (p. 17).

Apesar das conquistas do movimento, graças ao ativismo institucional e coletivo dos portadores, tais como distribuição gratuita de medicamentos e preservativos, as contradições da luta manifestam-se nas novas estruturas de organizações as quais:

"Apesar de continuarem sem fins lucrativos, não teriam as características que lhe valem o nome, terceiro setor/ONG, sem o mercado. Sem fins lucrativos porque supõe a existência do lucro em outro plano. Não houvesse a autonomia do mercado, não haveria a autonomia das organizações sem fins lucrativos". (Fernandes, 2004, p. 20).
Nesse sentido, os discursos dos usuários sobre as mudanças no funcionamento e atividades desenvolvidas pela ONG estudada, ou seja, a lógica privatista, o anonimato, o apoio dos usuários à execução de projetos, refletem o novo modus operandi da ação anti-AIDS caracterizada pela diminuição do estímulo para lutar, diminuição de voluntários, diminuição da freqüência do portador à ONG, abandono da mobilização em virtude da melhoria da qualidade do tratamento dos portadores, burocratização da ONG em virtude da execução de projetos e parceria Estado/ONG que, paradoxalmente, através dos financiamentos, deu visibilidade a luta anti-AIDS através de eventos com vagas limitadas em detrimento de atividades de rua e de eventos abertos e ampliados.

Portanto, enfatiza-se a opção do individual sobre o coletivo no sentido de que usar preservativo é um ato individual, mas o discurso sobre tal comportamento é apropriado pela coletividade. De acordo com Foucault (1979) a política de regulamentação dos corpos, o biopoder, é a primeira via para a qual o capital recorre. Para produzir, o capitalismo global e a soberania imperial é preciso controlar toda nossa existência, nossos desejos e modos de vida. O biopoder, segundo Revel (2005) se ocupará da gestão da vida e da força de trabalho, da saúde, da higiene, da alimentação, da sexualidade, da natalidade, etc. Refere-se a um controle sobre os corpos, uma economia do poder, voltada para "instalar um sistema de individualização que se destina a modelar cada indivíduo e gerir sua existência" (p. 30). Isso, certamente indica algo importante sobre os modos de subjetivação e os mecanismos disciplinares que atravessam a atualidade. Fala de padrões de sociabilidade e de controle social contemporâneos. Os usuários pesquisados revelam isso em seus discursos. Esse individualismo indica formas de assujeitamento contra as quais precisamos estar alertas e nos insurgir.

Segundo Pélbart (2000), o biopoder, ou poder de regulação da vida, administra o homem enquanto espécie viva nas cidades, na população, nas diversas instituições. Há uma diluição dos "muros" e o transbordamento da lógica de poder para outros setores da vida, fazendo-nos "prisioneiros a céu aberto" (p. 29). É nesse sentido também que Deleuze (1992) sugere que os poderes sobre a vida encontram-se diluídos hoje na chamada "sociedade de controle", através do cruzamento entre a norma da disciplina e a norma da regulamentação (operada pelo biopoder) e em relação às quais devemos responder com as "potências de criação da vida".

Grande parte do terceiro setor em HIV/AIDS passou paulatinamente, na década anterior, a ocupar o lugar dos movimentos sociais deslocando-os de seu espaço de luta e da preferência da adesão popular (Montaño, 2003, p. 271-274). Carregam as demandas populares não mais numa relação de luta, mas de "pedido" e "negociação" assumindo a representatividade das organizações soci- 
ais. Sob esta ótica, o portador passa a ser um alvo, uma perspectiva de lucro para o reordenamento de algumas ONGs. Para Terto Jr. (2004):

Mediante financiamentos transferidos para ongs, os governos acabam 'contratando' as organizações para realizarem serviços que deveriam continuar sendo executados pelos Estados. Nesse sentido, muitas organizações correm o risco de se tornarem executoras das políticas governamentais, funcionando como empresas para a prestação de serviços terceirizados. Tal relação pode levar a ong a se afastar de sua agenda de mobilização política, de resistência coletiva e de intervenção, e a se voltar para a agenda dos governos e dos setores governamentais que repassam financiamentos.

Assim, observa-se que a ONG pesquisada está atravessada no seu cotidiano pelos problemas da falta de adesão e desmobilização, na medida em que vem se afastando de uma agenda de mobilização para aproximar-se de setores governamentais que repassam financiamentos, através da execução de projetos. Como consequiência direta, a ONG não vem conseguindo mobilizar portadores para as atividades de rua. Isso representa somente, em nossa concepção, um indicador de enfraquecimento das forças de combate, mas não seu aniquilamento.

Sob essa ótica também compreendemos que a práxis militante vê-se solapada diante da opção pelo anonimato porque o portador de HIV passa a ser militante dele mesmo. Milita em busca da adesão ao tratamento, da regulação dos programas governamentais e da institucionalização que vai se dar através das atividades da ONG. A institucionalização desses sujeitos à ONG pesquisada os aprisiona na produção de consenso dos modos instituídos de trabalhar e viver. A partir da institucionalização, tornam-se enfraquecidos na busca da emancipação e aumento de potência de vida. Segundo Manfroi (1997):

"A luta pela cidadania dá-se como uma possibilidade de reverter o pilar da regulação para o da emancipação, em que redimensionam-se as lutas sociais e também os desejos. . . necessita de sujeitos sociais engajados e que, em grande medida, redimensionem também sua relação com o desejo do outro e consigo mesmo; que sejam capazes de se engajar como seres desejantes". (p. 277).

A visibilidade sucumbe ao anonimato quando a $\mathrm{ONG}$ sucumbe a novas formas de biopoder, dentre as quais situamos a produção de modos de existência privatizados e burocratizados. Assim, a ONG é um agenciador de formas de subjetivação que no embate cotidiano produz tanto resistências ao poder, quanto capturas, tanto usuários combativos no sentido de constituição do coletivo, do comum, quanto investidos em uma lógica individualizante. E aí reside seu maior desafio: identificar quais são as novas formas imperiais de domínio, suas estratégias. Manfroi (1997) afirma que "as novas formas de exercí- cio de poder (a disciplina), criam formas de subjetivação a partir da racionalidade administrativa, individualizando os sujeitos, os corpos coletivos com manipulação de emoções e sentimentos" (p. 280). Afinal, não é essa burocratização que assistimos na ONG investigada?

Outro aspecto relacionado à prática do ativismo anti-AIDS diz respeito à adesão individualizada ao tratamento como ferramenta de motivação para a luta antiAIDS. Para onde isso aponta, senão para a "eficácia das pequenas obediências conseguidas na modernidade... para a glorificação do súdito" (Passetti, 2004, p. 133)? Entretanto, essa prática individualizada não é rara e está sintonizada com os processos de produção subjetiva que vêm sendo gestados na contemporaneidade, os quais consistem na fabricação de modelos identitários fixos, na reprodução serializada de modos de existência, que certamente despotencializa agenciamentos de singularidades, pois ao estabelecer um modelo uniforme, ideal, universal, pressupõe a homogeneização das diferenças, desarticula ou perverte os espaços políticos de articulação.

Sendo assim, percebe-se quanto o biopoder é exercido dentro de boa parte das ONGs. Ao aderirem ao tratamento, os portadores realizam não um simples procedimento de saúde, mas assumem uma identidade. Passam a ser os monitorados, "o público alvo", os anormais, os que recebem tratamento e medicamentos gratuitos. São "os da ONG”. Os cadastrados nos serviços de saúde, que procedem caracterizando e outorgando o biopoder sobre seus corpos. Passetti (2004) indica que essa identificação é sustentada por pequenas e ininterruptas obediências e nela se afirma a ética da responsabilidade, onde "busca-se capturar cada um num módulo da rede, fazê-lo caminhar de um ponto a outro, apanhar o que pretende passar pelo fluxo gerando o gosto pelo lugar em que se ocupa ou almeja” (p. 133-134).

O portador, aconselhado, lançará mão das "técnicas" para tomar a medicação e assim se identificar com o tratamento e, conseqüentemente, com a adesão. Para Foucault (1979):

"O fio condutor que parece ser o mais útil, nesse caso, é constituído por aquilo que poderia chamar de 'técnicas de si', isto é, os procedimentos que sem dúvida, existem em toda civilização, pressupostos ou prescritos aos indivíduos para fixar sua identidade, mantê-la, ou transformá-la em função de determinados fins e isso graças a relações de domínio de si sobre si ou de conhecimento de si por si”. (p. 109).

Em outras palavras, a estrutura atual da ONG pesquisada e dos programas governamentais de combate à AIDS colocou o portador do HIV/AIDS como exercício central do biopoder. Não é por acaso que aderir ao tratamento e fazer prevenção a AIDS foi o modo que os portadores encontraram para lutar contra a doença. Nesse contexto Pelbart (2003) questiona: 
“...que possibilidade restam, nessa conjunção de plugagem global e exclusão maciça, de produzir territórios existenciais alternativos àqueles ofertados ou mediados pelo capital? ...De que recursos dispõe uma pessoa ou um coletivo para afirmar um modo próprio de reinventar a corporeidade, de gerir a vizinhança e a solidariedade, de cuidar da infância ou da velhice, de lidar com o prazer e a dor?" (p. 22).

As ONGs produzem subjetividade e encontram-se incluídas num cenário globalitário que as impede de produzir outros territórios existenciais e de referência para os portadores, criar e consolidar linhas de fuga da perspectiva de mercado, da homogeneidade e da perda da singularidade. A perspectiva de mercado é patente quando se recebe verba para executar projeto, a homogeneidade é manifesta quando os usuários dirigem-se à $\mathrm{ONG}$ apenas para participar de algumas atividades e a perda de singularidade é testemunhal quando os usuários estão aglutinados em torno das atividades festivas da ONG, por exemplo.

Omovimento estáreduzindo sua capacidade de aglutinar pessoas e executar ações de rua porque se esgota numa ação de gabinete, institucional, de contato e espera pelo governamental. O conhecer institucional suplanta o conhecer do sujeito implicado, quando deveria maquinar desejos de desinstitucionalização do militante. Questionamo-nos aqui se ainstitucionalização daAIDS foi inevitável. Tal questionamento parte da nossa percepção de que o movimento anti-AIDS se viu diante de duas ciladas: a cilada da institucionalização da AIDS e a cilada da parceria entre Estado/ONGs. É o esvaziamento político da própria ONG. Ou seja, "falta anarquia diante do templo" (Passetti, 2004, p. 136).

Presa a velhos clichês do movimento, embasada no tripé prevenção-cuidado-tratamento, algumas ONGs não conseguem sair do lugar comum e, contraditoriamente, fugindo da sua função de aglutinar pessoas em torno da causa anti-AIDS e da defesa da vida em sua plenitude, incluindo produção de subjetividade proporcionando novas formas de vida, de ver o mundo e de compartilhar a existência, assume a execução de projetos numa lógica burocratizante, despontencializada. Pelbart (2003) sobre tais clichês afirma que:

"as formas que antes pareciam garantir aos homens um contorno comum e asseguravam alguma consistência ao laço social, perderam sua pregnância e entraram definitivamente em colapso, desde a esfera dita pública, até os modos de associação consagrados ...e é quando eles assim esvaziados de sua pregnância, se revelaram como clichês, isto é imagens prontas, pré-fabricadas, esquemas reconhecíveis, meros decalques do empírico". (p. 28).

Portanto, para os usuários, em termos de concepção de ativismo, há diferentes perspectivas: realização de atividades ligadas à instituição (orientação, execução de projetos, atividades de rua), adesão ao tratamento e cuida- dos com a própria saúde. Em termos de prática de ativismo, observa-se: fazer prevenção, mudar de vida, participar de eventos, orientar pessoas e aderir ao tratamento. Deste modo, a análise nos leva a acreditar que há uma opção pelo anonimato calcada na lógica privatista porque as práticas coletivas estão desaparecendo e as individuais, como a adesão ao tratamento e o cuidado com a própria saúde, sobressaindo-se. Certamente estamos entendendo que esse cuidado afasta-se da perspectiva da pura adesão às prescrições e da obediência ao que é dito nas instituições. Estamos falando de um cuidar de si que "requer conhecimento, um comportamento e um modo de conduzir-se em relação aos demais, evitando abuso de poder (a tirania), a escravidão a seus desejos. Cuidar de si é governo de si e cuidado com os demais" (Passetti, 2004, p. 136).

Isso implica em um questionamento incessante que deve ser operado por usuários e técnicos acerca dos atravessamentos que imprimem uma lógica única de funcionamento da vida e consequentemente das técnicas de biopoder em operação no cotidiano que fazem com que as lutas, as resistências, tenham um gosto insosso diante das bárbaras e doces ofertas de apatia social.

\section{Notas}

1. Todos os nomes foram substituídos para resguardar a privacidade dos participantes.

\section{Referências}

Câmara, C., \& Lima, R. (2000). Histórico das ONGs/AIDS e sua contribuição no campo das lutas sociais [Edição especial]. $\mathrm{Ca}$ dernos $A B O N G, 10(28), 30-74$.

Castro, M. G., \& Silva, L. B. (2005). Respostas aos desafios da AIDS no Brasil: Limites e possibilidades. Brasília, DF: Unesco. Deleuze, G. (1992). Conversações. Rio de Janeiro, RJ: Ed. 34.

Fernandes, R. C. (2004). O que é o terceiro setor? Retrieved September 04, 2006, from http://www.rits.org.br

Foucault, M. (1979). Microfísica do poder. Rio de Janeiro, RJ: Graal.

Giddens, A. (2003). Mundo em descontrole: O que a globalização está fazendo de nós. Rio de Janeiro, RJ: Record.

Manfroi, V. M. (1997). Cidadania e subjetividade: Novos contornos e múltiplos sujeitos. São Paulo, SP: Imaginário.

Montaño C. (2003). Terceiro setor e questão social: Crítica ao padrão emergente de intervenção social. São Paulo, SP: Cortez.

Passetti, E. (2004). Pequenas obediências, intensas contestações. In E. Passetti (Ed.), Kafka, Foucault: Sem medos (pp. 123138). Cotia, SP: Ateliê.

Pélbart, P. P. (2000). A vertigem por um fio: Políticas da subjetividade contemporânea. São Paulo, SP: Iluminuras.

Pelbart, P. P. (2003). Vida capital: Ensaios de biopolítica. São Paulo, SP: Iluminuras.

Revel, J. (2005). Michel Foucault: Conceitos essenciais. São Carlos, SP: Claraluz.

Spink, M. J. P. (Ed.). (2000). Práticas discursivas e produção de sentidos no cotidiano: Aproximações teóricas e metodológicas (2. ed.). São Paulo, SP: Cortez. 
Farias, M. S. Q. de e Dimenstein, M. "Práticas e discursos de usuários de uma ONG/AIDS sobre ativismo

Spink, M. J. P., \& Lima, H. (2000). Rigor e visibilidade: A explicitação dos passos de interpretação. In M. J. P. Spink (Ed.), Práticas discursivas e produção de sentidos no cotidiano: Aproximações teóricas e metodológicas (2. ed., pp. 93122). São Paulo, SP: Cortez.

Terto, V., Jr. (2004). A sociedade civil e os desafios na terceira década da AIDS. Retrieved June 09, 2004, from http:// www.abiaids.com.br

Maio Spellman Quirino de Farias é mestre em Psicologia pela Universidade Federal do Rio Grande do Norte (UFRN). spellman@hs24.com.br

Magda Dimenstein é doutora em Saúde Mental pela Universidade Federal do Rio de Janeiro. Professora do Departamento de Psicologia da UFRN. Endereço para correspondência: Universidade Federal do Rio Grande do Norte, Centro de Ciências Humanas, Letras e Artes, Departamento de Psicologia, sala 610, Campus Universitário, Natal, RN, 59.078-970. Tel. e fax:

(84) 32153590.

magda@ufrnet.br

Práticas e Discursos de Usuários de uma ONG/AIDS sobre Ativismo

Maio Spellman Quirino de Farias e Magda Dimenstein

Recebido: 17/05/2007

$1^{\text {a }}$ revisão: $24 / 08 / 2007$

$2^{\mathrm{a}}$ revisão: $14 / 12 / 2007$

Aceite final: 18/12/2007 